\title{
The women who launched NASA
}

\section{Jennifer Light savours the history of a doughty band of 'human computers'.}

$\mathrm{D}$ ata is having its moment in the sun. It used to be an incidental detail in stories about personalities and institutions in the history of science and engineering, politics and culture. Now, the construction of databases and details of data analysis are featured events. Even the 2015 film Spotlight, which dramatizes a journalistic investigation into sexual abuse in the Catholic Church, has an extended scene in which the protagonists compile a spreadsheet. Number crunchers, once stereotyped as missing the bigger picture, now are the big picture.

Natalia Holt's Rise of the Rocket Girls reveals how, from the 1940s, a group of 'crunchers' operated in near secrecy at NASA - their anonymity as much to do with their gender as with the status of data. These women staffed NASA's Jet Propulsion Laboratory (JPL) in Pasadena, California, as human computers and, later, programmers. Most held degrees in mathematics or science. Their work, Holt reveals, was innovative, yet was considered less important than other JPL outputs. Holt documents the work of previously unknown figures such as Barbara Canright, Susan Finley and Helen Ling, who supplied crucial calculations that helped to launch missiles, bombers and the first US satellite; to control lunar missions; and even to navigate today's Mars rovers. Intercut with the human stories, Holt carefully lays out practical problems - such as the need to minimize fuel weight while ensuring that a rocket could reach escape velocity - and how mathematics helped to solved them.

Here, maths is dramatic, not mundane. Calculating is a physical, even athletic, act. Holt describes Canright's experience: "Her right index finger was lined with thick red and white calluses, the result of clutching a pencil for hours a day. Her grip on the pencil

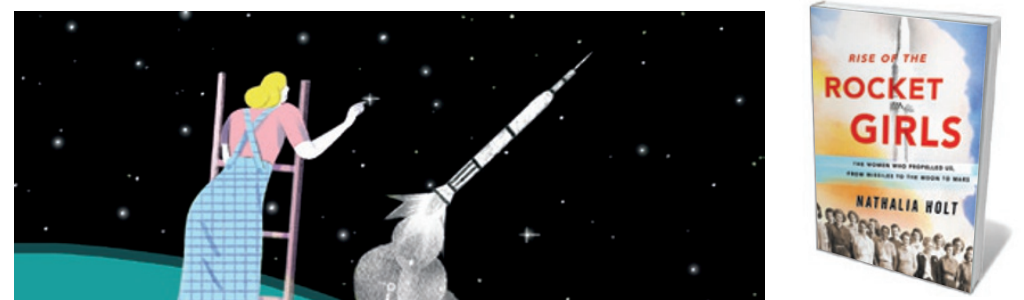

Rise of the Rocket Girls: The Women Who Propelled Us, from Missiles to the Moon to Mars NATHALIA HOLT Little, Brown: 2016.

Crowley realized that she had forgotten to take a square root. Her phone call came too late and the rocket failed luckily, no one was hurt. Often rushed and never double-checked in those seatof-the-pants days, the calculations were a source of anxiety for the women.

The drama of data is not the book's main rationale. Holt's larger interest is that it was women who did the calculating. The book is organized chronologically, with photographs of starring figures at the start of each section. In keeping with larger currents in historical studies of databases and data analysis, Holt argues that these women's calculations played an under-appreciated part in NASA's towering achievements. She bases her chronicle on interviews with several JPL data crunchers, members of their families and lab engineers, as well as a reading of scholarly and archival literature on the space programme.

The book does not show equal mastery of research on gender and labour in technical fields: Holt provides more

often made her hand perspire, leaving pucker marks across the graph paper." The women held "computing races" to solve complex mathematical problems in their down time. But as Holt shows, 'doing the maths' was often a matter of life and death. She describes Marie Crowley's work on the ideal size and shape of a rocket's nozzle opening: the faster a nozzle can clear exhaust, the more thrust the rocket generates. On one occasion, as engineers were about to run a test based on her calculations, data than analysis. She depicts the human computers' life stories vividly, but her reflections on larger themes are limited. One is the relationship between people and machines. For example, Holt mentions the women's limited use of calculation aids. They often found it faster to do hand calculations than to work with a Friden calculating machine. Even in the late 1950s, when JPL acquired an IBM 704 - an early mass-produced computer - the crunchers (and engineers) were

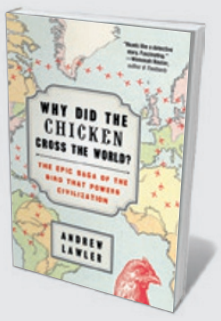

Why Did the Chicken Cross the World? Andrew Lawler (Atria, 2016) With 20 billion chickens roaming Earth at any one time, this beleaguered bird truly merits Andrew Lawler's illuminating eulogy. It shows how the red junglefowl (Gallus gallus) strutting in a Borneo jungle became an economic mainstay (see Ewen Callaway's review: Nature 515, 490-491; 2014).

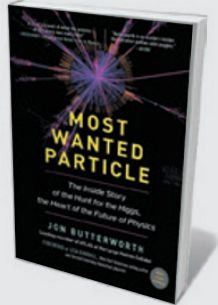

Most Wanted Particle Jon Butterworth (The Experiment, 2016) Experimental physics becomes accessible as well as astounding in this insider's account of the hunt for the Higgs boson, detected in 2012. Explaining fermions, jet algorithms and particle-accelerator malfunctions with ease, Jon Butterworth puts a lively spin on atomic science. 
wary of machines "that had too many glitches to be trustworthy". The speed and accuracy of later models threatened to make the mathematicians' roles redundant, but the women staved off obsolescence for some time by redefining their official jobs as programmers. Holt misses an opportunity here to make the connection between the experiences of JPL's human computers in relation to the rise of automation, and today's widespread anxieties over the 'age of artificial intelligence'.

Personal anecdotes include details of the family arrangements that the women had to make in an era when marriage and children meant leaving the workforce. These will fascinate general readers and provide valuable primary source materials for future academics. Yet Holt does not contextualize the JPL crunchers' experience in the broader history of women in science and technology. She does observe that the proportion of JPL technical jobs held by women - 15\% in the 1990 s - was partly due to women organizing the hiring process. Yet although the figure was higher than elsewhere in NASA, it was still remarkably low. And in the same way that NASA failed to celebrate these women's contributions, it also overlooked the evidence in favour of including women in the astronaut corps. As space curator Margaret Weitekamp has detailed in Right Stuff, Wrong Sex (Johns Hopkins University Press, 2004), the benefits of sending women to space included their small size compared to men, which meant that they would need less food and water.

Engagement with such studies would have helped Holt to analyse how typical the JPL programmers' experience was for women in technical fields, and to explicate her original findings more clearly. Many scholarly studies describe the exodus of women at other institutions from programming by the 1950s. By contrast, Holt notes, some of the early female crunchers stayed at JPL well into the twentyfirst century, some in managerial roles. That raises questions about what made JPL different and, crucially, about retaining women in technical fields today. That story remains to be written.

Jennifer Light is professor of science, technology and society at the Massachusetts Institute of Technology in Cambridge. e-mail:jslight@mit.edu

\section{Coitus defunctus}

\section{Lori Andrews assesses Henry Greely's treatise on how technology will oust reproductive intimacy.}

$\mathrm{F}$ or millennia, people have been trying everything from magic to medicine to influence the traits of their children. Recommendations from relatives and advice columns have, across time, included: put a knife under your bed if you want a boy; eat sweets while pregnant if you want a girl; place headphones on your pregnant belly and play Jacopo Peri's Euridice to ensure that your future child will appreciate opera.

Current genetic technologies offer parents more-precise means of predicting and perhaps shaping the traits of their children. Embryos created through in vitro fertilization (IVF) can be analysed using pre-implantation genetic diagnosis (PGD); their entire genomes can even be sequenced. And the gene-editing technique CRISPR-Cas9 is expected to one day offer couples a chance to repair and enhance the genes of their embryos.

In The End of Sex and the Future of Human Reproduction, lawyer and bioethicist Henry Greely does an enviable job of explaining the scientific underpinnings and legal regulation of current reproductive and genetic technologies. The central focus of his book is his prediction that a new technology will develop - one that he dubs "Easy PGD". Greely envisions a situation in which a woman will not have to undergo treatment with hormones and have her eggs removed to produce an embryo for testing - as is done in the course of IVF. Instead, some of her skin cells will be removed and coaxed by stem-cell technologies to turn

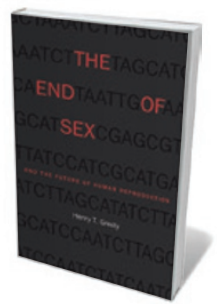

The End of Sex and the Future of Human Reproduction HENRY T. GREELY Harvard University Press: 2016.

into eggs. The eggs will then be fertilized by sperm from her partner to create as many as 100 embryos. In this scenario, parents will be able to choose which embryos to have implanted in the woman's uterus on the basis of hundreds of traits (or more) revealed by whole-genome sequencing.

Greely makes three claims about this putative Easy PGD. First, it will replace sex as a way to create babies. Second, it will be more socially acceptable than current PGD and prenatal genetic-testing technologies. And third, it will be free to the user.

All three claims are problematic.

Greely assumes that people will elect to create children with Easy PGD rather than through sex because of the desire to control the traits of their children. But if people were so keen to choose embryos on the basis of their genotypes, all couples who use IVF would submit their embryos to genetic testing (given that this would involve no extra risk to the woman). In the United States, only $5 \%$ of such couples do so.

Greely also speculates that couples will rush to use stem cells to create embryos because such an approach would be less

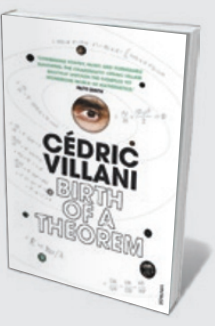

Birth of a Theorem: A Mathematical Adventure Cédric Villani (Vintage, 2016)

Tackling the 140-year-old Boltzmann equation (with Clément Mouhot) led mathematician Cédric Villani to win a share in the 2010 Fields Medal. Documenting this quest, Villani encapsulates the despair and elation that maths can incite (see Amir Alexander's review: Nature 519, 31-32; 2015).

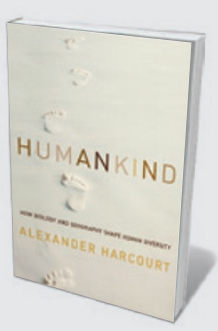

Humankind: How Biology and Geography Shape Human Diversity Alexander Harcourt (Pegasus, 2016) Biogeographer Alexander Harcourt ponders the myriad forces that led to the amazing diversity of Homo sapiens as we spread across the globe. He thinks that coastal migration once prevailed: harvesting seafood was easier than hunting. 